\title{
STUDY OF VITAMIN D LEVELS IN ADULT MALES IN DAKAHLIA GOVERNORATE in EGYPT
}

Authors Raef M. Botros *,Rania Sayed", Merhan Samy* and Mohamed Yassin *

Hospital *Department of Medicine, Ain Shams University Hospital

\section{OBJECTIVES}

Vitamin D is a growing endemic problem. Wide proportions of healthy adults are deficient in vitamin $D^{1}$. Previous studies done in Egypt had demonstrated wide prevalence of hypovitaminosis D in Egyptian females in the child bearing period living in Cairo ${ }^{2}$ as well as in different age groups living in PortFouad ${ }^{3}$. So we aimed at assessing vitamin-D sufficiency / deficiency in a sample of healthy Egyptian adult males in Dakahlia Governorate in Northern Egypt and correlate it to social status, Sun exposure and Vitamin D intake in food.

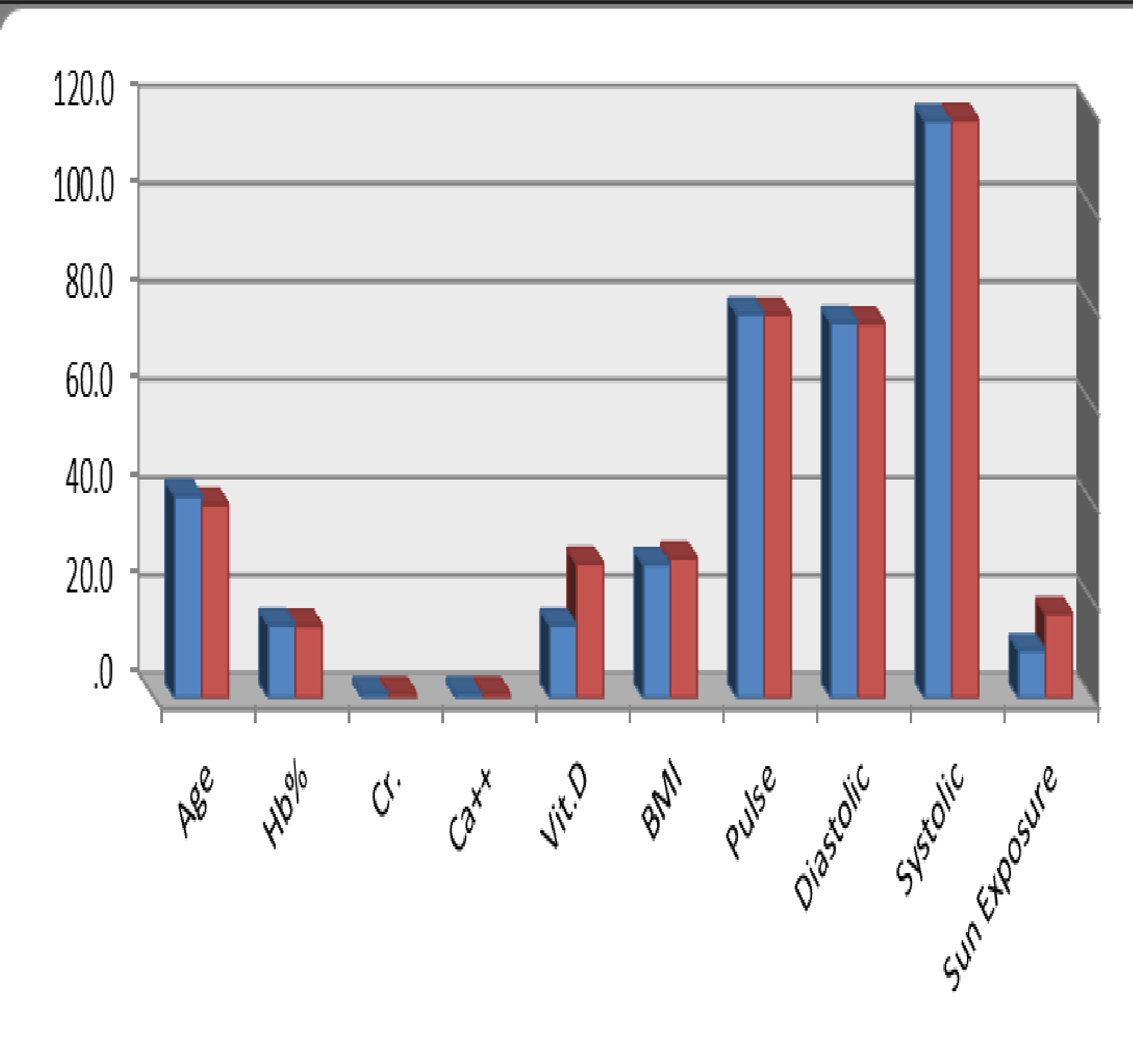

Indoor Moutdoor
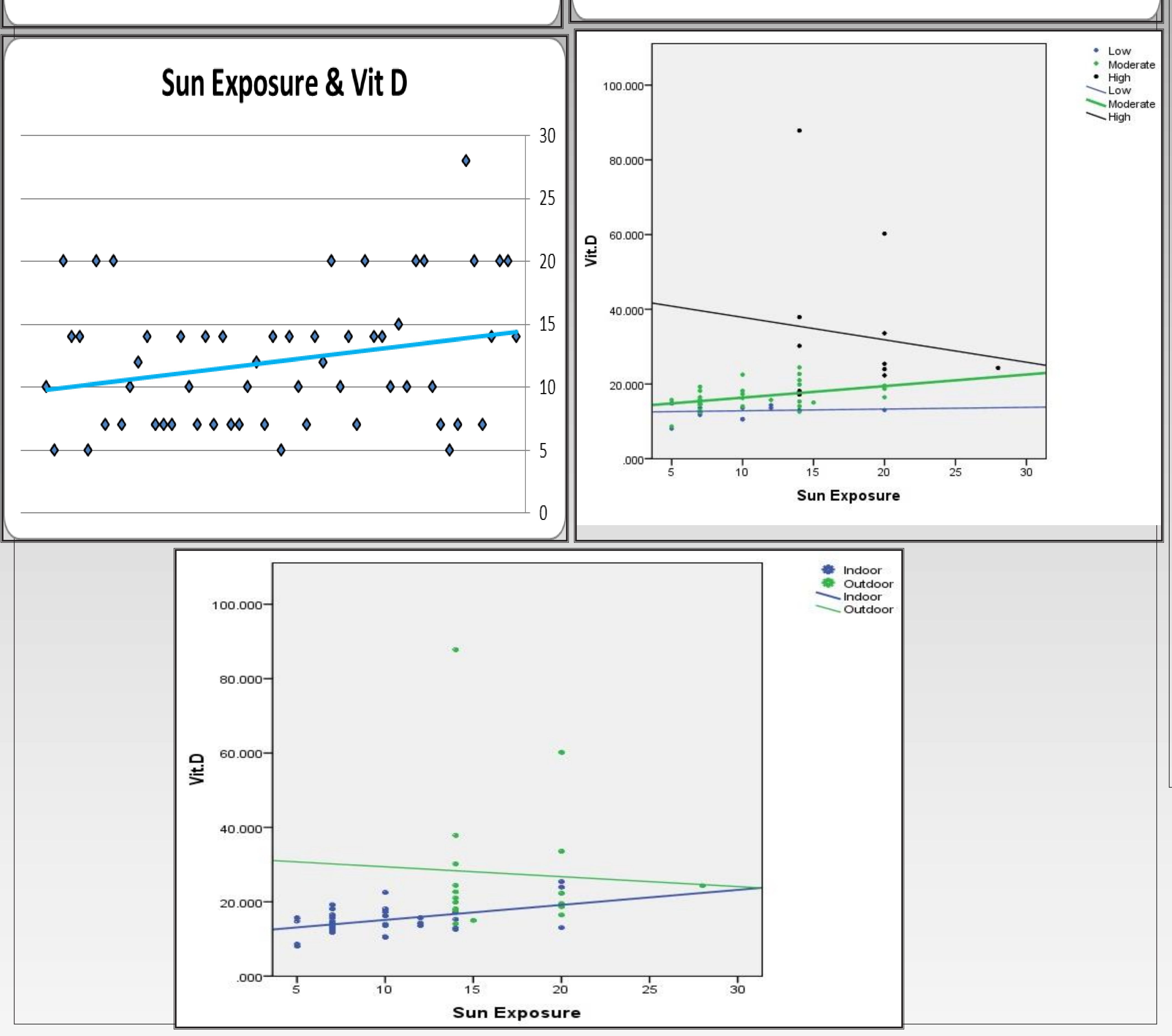

\section{CONCLUSIONS}

Our results show a high rate of hypo-vitaminosis D in adult Egyptian Males in Dakahlia Governorate. Sun exposure was found to be the most dependent risk factor for this hypovitaminosis $D$.

\section{METHODS}

This cross-sectional study was conducted on 90 healthy Males selected randomly from the relatives of patients in Outpatient Clinics and Internal Medicine Departement of El-Gamalia General Hospital. Medical History, Dietary Questionnaire and Sun exposure Questionnaire were taken from all participants who were clinically examined as well. Laboratory investigations including hemoglobin, serum creatinine, ionized calcium were measured in all subjects and 25-(OH) vitamin D was measured in 57 subjects

\section{RESULTS}

In our study, $67.8 \%$ of subjects were middle privileged, $31.1 \%$ underprivileged and $1.1 \%$ as privileged $.80 \%$ had hypocalcaemia while $20 \%$ had normal calcium level .Vitamin D level was assessed in $\mathbf{5 7}$ subjects. $77 \%$ had deficient vitamin D , 14\% with insufficient vitamin D 9\% with sufficient vitamin D $55.6 \%$ of our subjects had moderate intake of vitamin D rich foods while $18.9 \%$ had high intake and $25.6 \%$ had low intake. $59 \%$ had indoor occupations while $41 \%$ had outdoor occupation. Average sun exposure was 13.1 \pm 5.5 hours weekly. On comparing vitamin $D$ deficient and insufficient groups, deficient and sufficient groups there were no significant differences except for sun exposure, $(\mathrm{p}<0.001, \mathrm{p}=0.008$ respectively $)$.
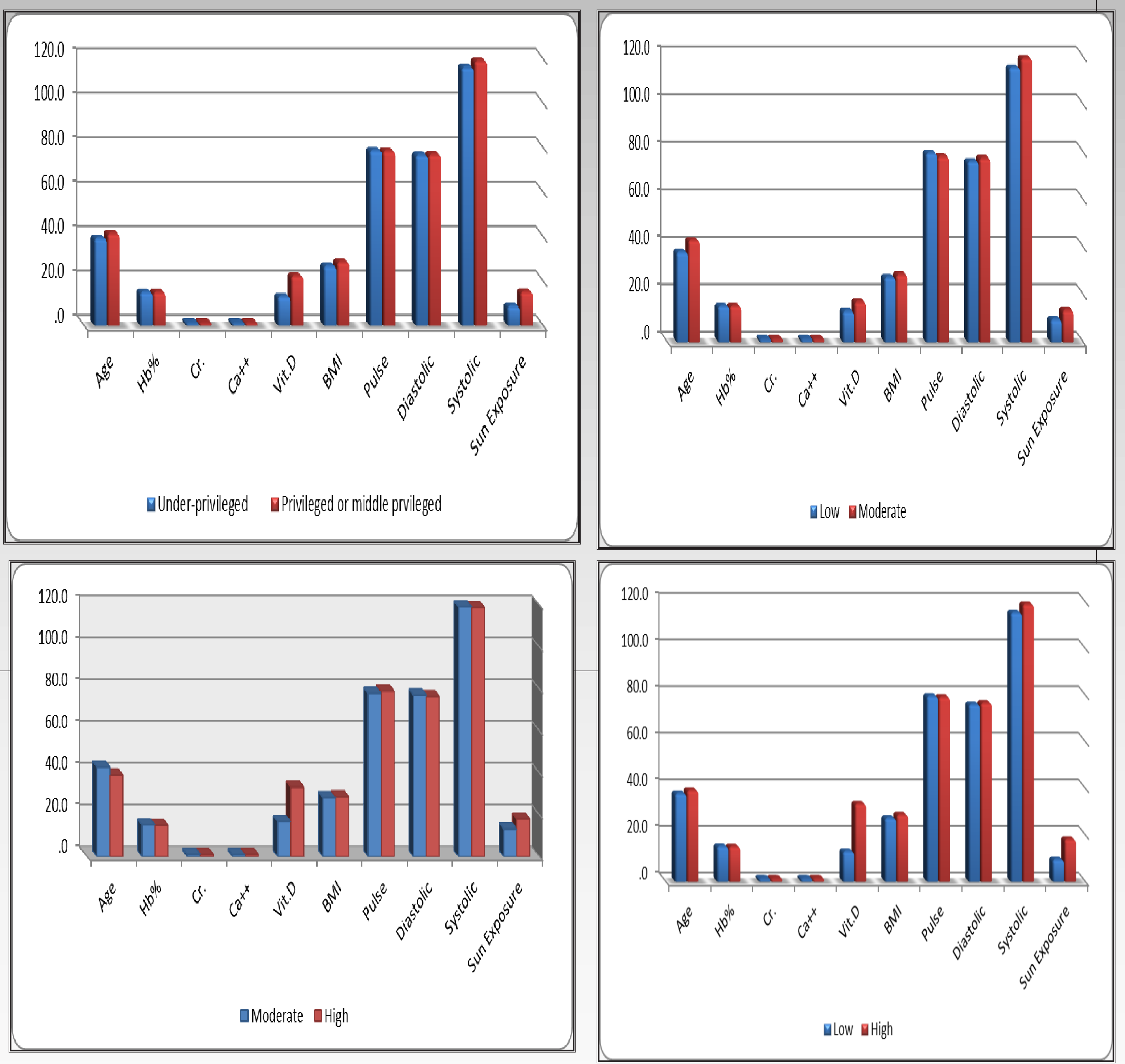

\section{REFERENCES:}

1-Holick MF (2007): Vitamin D deficiency.[see comment]. N Engl J Med.; 357:266-281

2-Botros RM, Sabry IM, Anis MM, Mattar MR (2011): Sufficiency of vitamin D among Egyptian females in child bearing period. PhD Thesis, (MSc Dissertation), Ain Shams University.

3-Botros RM, Hosny SS , Anis MM, Elmetwaly AE (2011): Assessment of vitamin D status in females in different age groups in Port-Fouad area. PhD Thesis, (MSc Dissertation), Ain Shams University. 